\title{
Convention and Exhibition Industry: Digitalization and Strategic Leadership During the COVID-19 Crisis and After the Pandemic
}

\author{
Olga Nikitina, ${ }^{1, *}$ \\ ${ }^{1}$ Faculty of Service, Tourism and Hospitality, Saint Petersburg State University of Economics, Saint Petersburg 191023, \\ Russian Federation \\ *Corresponding author. Email: maol@ rambler.ru
}

\begin{abstract}
The research this paper focuses on is devoted to the study of companies that lead the world market of congress and exhibition services. The research involved case-study, benchmarking, trend analysis, comparative analysis and other methods. The study revealed the leading companies and their leadership strategies. The global COVID-19 crisis calls for reviewing the work of congress and exhibition companies both at the time of the pandemic and after it. The author of the article considers the cases of the leading companies during the pandemic and their anti-crisis strategies conceived to meet the COVID challenges.
\end{abstract}

Keywords: Convention and exhibition industry, leadership strategies, COVID-19 challenge, sustainable development of convention and exhibition companies.

\section{INTRODUCTION}

The congress and exhibition industry are one of the most dynamically developing economic domains in the world, because exhibitions, congresses, conventions and conferences become fully-fledged participants in the global economic development of any country [1]. Such events today are considered to be an important formative factor that affects not only the economic potential of companies, industries, cities and countries, but also a key contributor to their sustainable development and leadership [2]. In addition, one has to note that they are distinguished by a high degree of digitalization and penetration of the tools and methods of the digital economy.

In the congress and exhibition industry, most leadership research focuses on motivational factors and staff interaction skills in teamwork [3], as well as the study of personal characteristics of managers and project leaders [4]. In the meantime, the majority of company leaders are well aware that in order to turn their company into a market leader, it is necessary not only to focus on management leadership and teamwork, but also to carefully build market leadership strategies in a rapidly changing environment [5].

Therefore, the congress and exhibition industry turn out to be an enticing research area in the sphere of leadership due to its unique ability to quickly adapt to the changes and challenges of the external environment.

This paper focuses on the main issues and provisions described above and provides evidence as well as practical examples from the field.

\section{LEADERSHIP, DIGITALIZATION AND STRATEGIC PRIORITIES}

About 31, 000 exhibitions are held annually around the world. There are over 4,4 million exhibits and more than 260 million visitors there [6].

According to the report "Top 20 exhibition organisers": the global ranking", provided by AMR, the leading consulting agency in the global event industry [7], the leading positions in the industry in terms of revenues and M\&A activities remain unchanged.

The company Informa Markets retains its first-place ranking, followed by Reed Exhibitions, while Messe Frankfurt concludes the top three.

Figure 1 that follows shows the AMR Top 20 exhibition organisers by exhibition-organising revenue. The Figure displays the leaders of the industry as of the closure of the two-year cycle of 2018-2019.

According to the expert opinion of Rankine, executive chairman of AMR International, the leading players are now competing to expand their activities [8]. The leading companies use different strategies to achieve their goals. Depending on the approaches to building leadership strategies in the market of congress and exhibition services, two groups can be distinguished according to their strategic preferences.

The first group is represented by such companies as Reed Exhibitions, Messe Frankfurt, Messe Dusseldorf, Messe Munich and CFTC that adhere to the organic growth strategy by developing at the expense of in- 
creasing their overall production and international expansion through geo-clones.

The second group includes, for example, Informa, Clarion and Emerald, that employed alternative leader- ship strategies of scaling their activity though merger and takeover transactions, and strengthened their geographical and sectoral positions by purchasing strategically important assets.

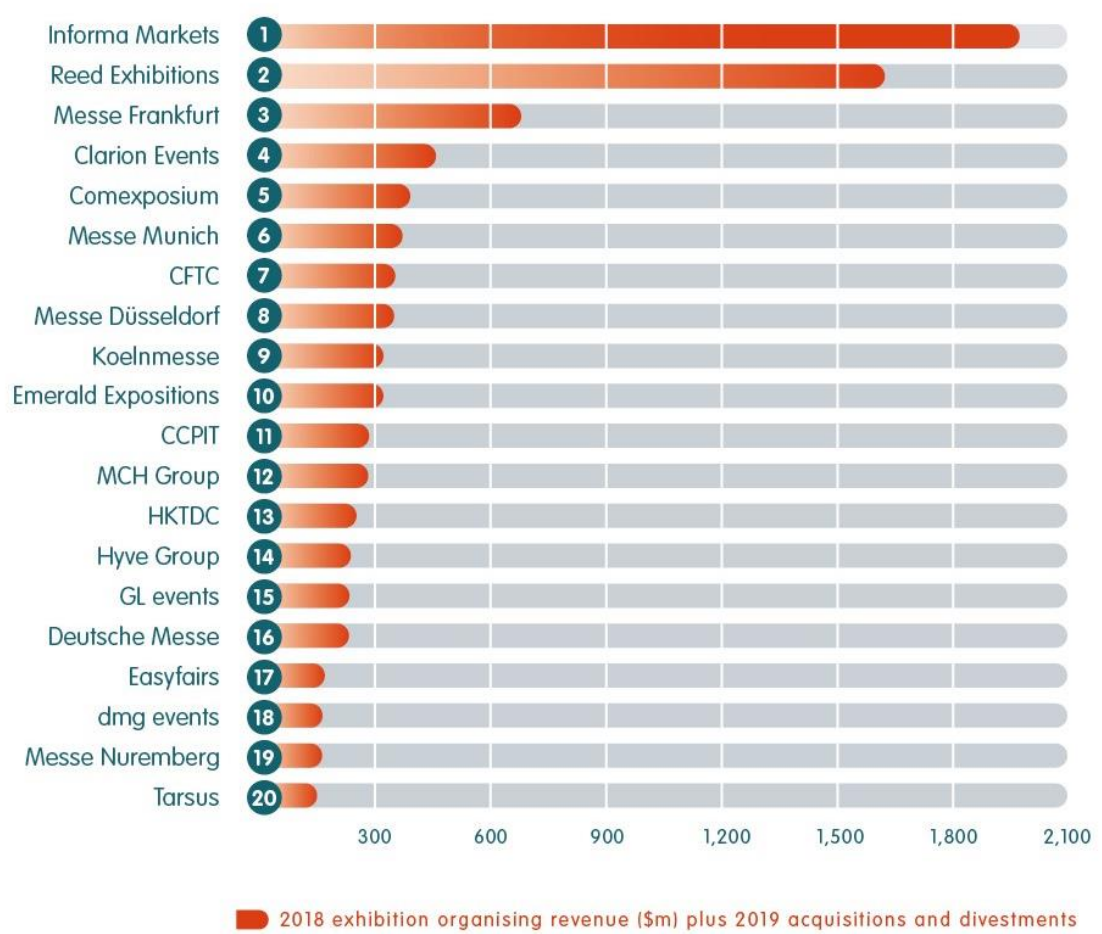

Update: Restated revenues sees Jaarbeurs fall out of the Top 20 and replaced by Tarsus.

Notes on methodology

- AMR estimates of pro-forma exhibition-organising revenues only, including AMR estimates of 2019 acquisitions and divestments.

- Excludes integrated revenue from venue rental to third party organisers, and all other non-core exhibition services.

- Converted at an average 2018 exchange rate.

Figure 1 The AMR Top 20 exhibition organisers by exhibition-organising revenue

The permanently changing global environment offers companies new opportunities, sets new strategic priorities and requires innovative approaches to congress and exhibition business. According to a survey conducted by the Statista agency [9] that involved over 380 respondents representing major congress and exhibition companies, the strategic priorities in the global congress and exhibition industry include the following groups.

Priority 1 - "Glocalisation of events" - a trend of globalisation that manifests itself in the way production, services and consumption of universal goods adjust themselves to the specifics of local markets. The trend involves starting such processes at regional enterprises on the basis of interregional cooperation. It means that new kinds of activities must be added to the range of orthodox products and services in the congress and exhibition industry; a special focus must be made on cross-sector initiatives in order to create an optimal number of links between the exhibitors and visitors, on the one hand, and the external environment - on the other hand. It will increase the number of event stakeholders and integrate it with the regional, national and global products and services.

It should be noted that this trend is the object of scientific research in the industry [10], and is effectively implemented by congress and exhibition companies.

Priority 2 - "Digitalisation and hybridisation of events" - represents new hybrid "dual" formats of events accompanied by all types of digital technologies and Artificial Intelligence. The implementation of "dual strategies" in the course of exhibitions, fairs, congresses and seminars should become the new norm: any event should be equally represented both in real-life and virtual formats. It is noteworthy that this strategic direction is developing very fast, because hybrid event forms make it possible to bring consumers as close as possible 
to manufacturers, to markets, and to boost the number of exhibition or congress participants.

The strategic priorities stated above require "proactive" changes on the part of all players in the struggle for leadership on the market of congress and exhibition services.

When asked if they were ready to embrace change in their own companies, $57 \%$ of the survey respondents said they are ready for full-scale "glocalisation" and "digitalisation" of their products and services; $24 \%$ of the respondents said they are ready to focus on "digitalisation" and move from demonstration-type congress and exhibition projects to interactive, virtual or fully open digital exhibition projects; $14 \%$ stated that their companies intend to retain their current activities, $5 \%$ of those questioned expressed their willingness to make use of "virtual" tools in isolated projects [9].

Based on the data of the international survey conducted by Statista we can assume that companies that choose the first two strategies of those mentioned above are actively participating in the struggle for leadership, which opens up new opportunities for increasing the competitiveness of companies on the congress and exhibition services market in response to external challenges.

Problem Statement. In February 2020, the World Health Organization announced a pandemic of the coronavirus infection "COVID-19" was spreading rapidly around the world.

At the time of the pandemic, the congress and exhibition industry which is directly related to interaction between people turned out to be one of the most vulnerable spheres, since organization of fairs, exhibitions and conferences is affected by all possible restrictions in tourism, transportation, and the ban on holding mass events.

The quarantine measures hugely affected economic activity in the congress and exhibition industry: current events were cancelled, upcoming events were suspended until further notice; the largest companies will receive a significantly smaller income, and many small and medium-sized businesses will not be able to overcome the crisis on their own; for some companies, bankruptcy looms on the horizon; many industry employees have already lost their jobs this year.

Globally, as of today, the total number of cancelled or postponed events due to the coronavirus pandemic includes 3,770 fairs and exhibitions: 2,174 in Europe (803 only in Germany), 896 in Asia, 517 in North America, 68 in South America, 7 in Africa, 38 in Australia [11].
In July 2020, the World Exhibition Association (UFI) published updated global data reflecting the impact that cancellations and rescheduling of exhibitions have had on the convention and exhibition industry around the world [12]. According to the study, $85 \%$ of companies claimed that compared to January 2020, when their overall activity level was "normal", owing to the pandemic, their business activity in March fell to $15 \%$ and reached an all time minimum of $5-6 \%$ in April, May and June. In addition, $73 \%$ of companies reported lack of business activity whatsoever in May and June 2020. According to UFI forecasts [12], the industry revenues around the world in 2020 are expected to reach only $39 \%$ of those in 2019 . The sharp drop in revenue that occurred in the first half of 2020 has already led to losses for $39 \%$ of companies. $44 \%$ of the companies in the study stopped all their investments in current operations. At the same time, in order to ensure the opportunity of working online, $50 \%$ of companies had to increase their investments in programs for the digitalisation of congress and exhibition projects. Despite the measures taken to transform their operations, only $7 \%$ of companies currently expect stable or increased profits in 2020 due to the "digitalisation" of their products.

It is obvious that no one can offer accurate forecasts for possible scenarios after the COVID-19 crisis, so companies need to accept the new reality, identify and estimate major risks and learn not only how to survive, but also to take the lead in the COVID-19 crisis and after the pandemic is over. The financial crisis of 2008 made many people doubt the necessity of financial spending on organizing or participating in business events under these circumstances. However, the subsequent analysis of post-crisis practical experience revealed that during this period the companies that were able to realize their potential by increasing business activity in convention and exhibition events, applying development strategies in adjacent and new markets, and not by economizing on convention and exhibition activities, were most successful [13].

\section{LEADERSHIP AT THE TIME OF COVID-19: A CASE STUDY}

The COVID-19 crisis has caused a dramatic decline in the business activity of companies on the market of convention and exhibition services around the world.

However, despite the decline in business activity and an objective reduction in the number of players on the congress and exhibition services market, the COVID-19 crisis has opened up new opportunities for companies and posed new challenges to gain or maintain leadership on the market. 
The study examined the cases of the world's leading trade exhibition organizers including Informa Markets, Reed Exhibitions; China Foreign Trade Center (CFTC).

Informa Markets Leadership Strategy. The company is the world's leader in terms of both revenue and the number of events, with an annual portfolio of around 550 exhibitions. The company employs over 4,400 people worldwide. For the period from August to December 2020, Informa Markets held 459 digital events, 265 events out of those were held in Asia, 34 in Europe, 19 in the Middle East and Africa, 65 in North America (60 in the USA) and 21 events in South America.

Early in 2019, the company launched a global marketplace to serve all of its branded exhibition projects in digital format in 15 areas, including Agriculture, Healthcare and Pharmaceuticals, Infrastructure, Construction and Real Estate, Aviation and Space, Health \& Nutrition and others [14].

Informa Markets is actively using the strategy of "Glocalisation", i.e. for each direction, a different approach is chosen, which takes into account the specifics of a particular region (country) to display local brands.

For example, as part of the Health \& Nutrition division which includes popular brand names such as Natural Products Expo, SupplySide and Food Ingredients (FiNA), Informa Markets has launched MarketReady Insights, a digital consulting platform that enables startups or companies approaching the US market for the first time and interested in promoting their local or national brands in the US market, to get expert advice on regulatory issues related to entering the market, expanding their business, supply chain security or contract manufacturing, certification, digital marketing and advertising their products in the United States. As part of the MarketReady Insights platform for small businesses, acceleration programs launched by Informa ensure product labelling in accordance with the requirements of the American market.

The case clearly demonstrates why Informa Markets is an absolute leader and continues to increase its profits during the COVID crisis: the company's strategic goal is to scale and strengthen its geographic spheres of influence by providing a unique opportunity for small, medium and large businesses at advantageous conditions to develop new markets for their products and services.

Reed Exhibitions Leadership Strategy. According to the AMR International report, the company comes second in the world ranking of exhibition companies. The company operates in about 30 countries and employs over 4,200 people worldwide. The company's annual portfolio includes 500 trade exhibitions and fairs, of which $94 \%$ are professional industry events in the B2B segment. In addition to exhibition projects, the company implements independent digital projects such as Imbibe, InfosecurityMagazine and Retail Design World, which offer additional benefits for the company's clients from among exhibitors, participants and event visitors [15]. For example, the Imbibe web portal is a niche virtual international online platform for festivals, workshops, conferences dedicated to the world's leading brands of spirits. The digital interactive service InfosecurityMagazine was launched by the company back in 2014. During the COVID-19 pandemic InfosecurityMagazine became a consulting assistant for the company's clients on creating jobs during the period of remote work. In addition, the service provides clients with solutions for corporate information security and warding off cyber risks during the period of remote work of employees, as the number of hacker attacks increased significantly during this period. Another digital service called Essential Retail during the COVID-19 pandemic provided the company's clients with recommendations for the safe opening of retail stores, agencies and restaurants after quarantine measures are lifted through a series of online webinars, virtual round table discussions with experts in medical, financial, legal and other aspects of work of retail companies.

It should be noted that for the second half of 2020 , Reed Exhibitions has an impressive portfolio of events, including 220 events around the world. The company describes their format as "dual" (or hybrid). That is, the event is first held offline with a limited number of participants in compliance with all COVID security measures, and then a few days later the event goes online for 2 or 3 days to involve a wider audience.

Considering this case, we will highlight the following leadership strategies that Reed Exhibitions sets for itself. First, the company wants to achieve high efficiency and boost client loyalty, because it is committed to its clients. That is why the leading company tries to pay attention to everyone, and offers many options for special services and programs to support clients around the world during the COVID crisis. Secondly, the company applies "digitalisation and hybridisation" to all of its products launched in 2020, which allowed it not only to maintain, but also to expand its exhibition portfolio and beat its competitors.

China Foreign Trade Centre (CFTC) Leadership Strategy. In the global AMR rating, CFTC ranks 7th [7]. CFTC is funded by the government of the People's Republic of China and is in charge of the biggest exhibition centre in Asia called Canton Fair Complex (Guangzhou Province), Shanghai International Convention Centre and other centres affiliated with CFTC. Despite the gravity of the situation with the pandemic in China and around the world, CFTC managed to effec- 
tively conduct all the scheduled events starting as early as April 2020.

While considering the leadership strategies of CFTC on the world market we must admit it has created a comprehensive virtual platform of the international level called "Smart Canton Fair". It has been under development since 2016. Due to this work, the 127th China Import and Export Fair (commonly known as the Canton Fair) scheduled for June 2020 was not cancelled, but successfully held online with minimum yet profound preparation of 2 months. Smart Canton Fair united a record number of wholesale buyers from 217 countries and regions. The fair aimed to promote goods made in China, and familiarize global consumers with Chinese brands. About 26,000 Chinese and overseas exhibitors uploaded nearly 80,000 products online in text, graphics, video and 3D, showcasing high-tech, multi-profile products made in China.

During the virtual exhibition spanning 10 days, exhibitors showcased their products $24 / 7$, and got many inquiries and orders from all over the world. Chinese plants, factories, workshops, warehouse centers for finished products managed to broadcast footages about production, storage, and logistics of their goods in real time. The average amount of video content from businesses was around 1,300 streams per day. Various supporting events were organized, including 24 Cloud Promotion events for global shoppers, 5 virtual trade signing ceremonies, 13 live virtual lectures, 150 virtual factory tours, 64 events including WeChat promotional activities, live streaming and flash sales [16].

\section{CONCLUSIONS}

All in all, the research and the case studies focusing on the global leaders in the sphere of congress and exhibition services enable us to posit that many of them adhere to identical strategies.

Their primary goals include the intention to scale up their activity and strengthen their geographical and sectoral market positions by increasing their performance and output, applying the strategy of organic growth or its alternatives, by expanding the production of congress and exhibition services due to takeovers and mergers.

While setting their second-order goals, the market leaders display proactivity, try to detect new trends and enter into creative synergy with all the parties involved - exhibitors, participants, visitors, subcontractors and suppliers. Such an approach enables the leading companies in this sphere to review and redesign their activities through diverse collaborations with different stakeholders and adapt their products to new challenges.
The strategic priorities described above, such as "glocalisation", "digitalisation", "hybridisation" of events and "commitment to clients" are components of the leadership strategy, that enable these companies not only to work smoothly at the time of the pandemic, but also to expand their activity.

\section{ACKNOWLEDGMENTS}

This publication was prepared within the scope of the research project No. GSGK-31/19 with the support of the V. Potanin Charitable Foundation "Management of the infrastructure of the congress and exhibition services market".

\section{REFERENCES}

[1] D. Getz, Event studies: Theory, research and policy for planned events, Routledge, 2012, 442 p.

[2] T. Pernecky, Sustainable leadership in event management, Event Management 19 (2015) 109-121. DOI:

https://doi.org/10.3727/152599515X14229071393188

[3] P.G. Northouse Leadership, Theory and practice, Sage Thousand Oaks, 2004, 504 p.

[4] M. Giudici, V. Filimonau, Exploring the linkages between managerial leadership, communication and teamwork in successful event delivery, Tourism Management Perspectives 32(October) (2019) 100558. DOI: https://doi.org/10.1016/j.tmp.2019.100558

[5] D. Vera, M. Crossan, Strategic leadership and organisational learning, Academy of Management Review 29(2) (2004) 222-240.

DOI: https://doi.org/10.5465/amr.2004.12736080

[6] Allostand (2018) Who are the biggest trade fair organizers of the world? https://www.allostand.com/en/who-are-the-biggesttrade-fair-organizers-of-the-world/ Accessed on 1 Aug 2020

[7] AMR International (2019) "Top 20 exhibition organisers": the global ranking. https://amrinternational.com/amr-top-20-october2019/ Accessed 1 Aug 2020

[8] Exhibit City News (2017) Reed Exhibitions, UBM, Top World's Largest Exhibition Organizers https://exhibitcitynews.com/reed-exhibitions-ubmtop-worlds-largest-exhibition-organizers/ Accessed on 5 Aug 2020

[9] Statista (2017) Strategic activity priorities of the exhibition industry worldwide as of January 2017. https://www.statista.com/statistics/37 8538/strategic- 
activity-priorities-of-the-exhibition-industryworldwide/ Accessed on 15 Sep 2017

[10] B.K. Dawson, L. Young, Ch. Tu, F. Chongyi, Co-innovation in networks of resources - A case study in the Chinese exhibition industry, Industrial Marketing Management 43(3) (2014) 496-503. DOI: https://doi.org/10.1016/j.indmarman.2013.12.017

[11] Expocheck (2020) Coronavirus leads to exhibition cancellations. List of postponed or cancelled trade fairs and exhibitions worldwide https://www.expodatabase.de/en/articles/125890-

coronavirus-leads-to-exhibition-cancellations Accessed on 31 July 2020

[12] UFI (2020) 25th UFI_Global_Barometer, July, 2020 https://www.ufi.org/wp-

con-

tent/uploads/2020/07/25th_UFI_Global_Barometer_j uly_2020_v1.pdf Accessed 1 Aug 2020

[13] N. Ferdinand, P.J. Kitchin, Events in our changing world. Events management: An international approach, SAGE, 2012, pp.5-22.

[14] Informa Markets (2020) Working in specialist markets.

https://www.informamarkets.com/en/markets.html Accessed 1 Aug 2020

[15] Reed Exhibitions UK (2020) UPCOMING EVENTS https://www.reedexhibitions.com/reedexhibitions-uk/about-us Accessed on 1 Aug 2020

[16] CFTC (2020) News on Canton Fair https://www.cftc.org.cn/en/News/NewsonCantonFair/ Accessed on 1 Aug 2020 